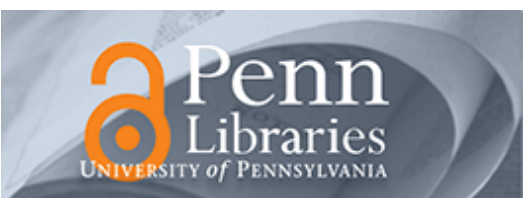

University of Pennsylvania

ScholarlyCommons

April 2001

\title{
The measurement of regional cerebral blood flow during the complex cognitive task of meditation: a preliminary SPECT study
}

Andrew B. Newberg

University of Pennsylvania, andrew.newberg@uphs.upenn.edu

Abass Alavi

University of Pennsylvania, ALAVI@OASIS.RAD.UPENN.EDU

Michael J. Baime

University of Pennsylvania, baime@mail.med.upenn.edu

Michael Pourdehnad

University of Pennsylvania

Jill Santanna

University of Pennsylvania

See next page for additional authors

Follow this and additional works at: https://repository.upenn.edu/neuroethics_pubs

\section{Recommended Citation}

Newberg, A. B., Alavi, A., Baime, M. J., Pourdehnad, M., Santanna, J., \& d'Aquili, E. (2001). The measurement of regional cerebral blood flow during the complex cognitive task of meditation: a preliminary SPECT study. Retrieved from https://repository.upenn.edu/neuroethics_pubs/25

Postprint version. Published in Psychiatry Research: Neuroimaging, Volume 106, Issue 2, April 2001, pages 113-122.

Publisher URL: http://dx.doi.org/10.1016/S0925-4927(01)00074-9

This paper is posted at ScholarlyCommons. https://repository.upenn.edu/neuroethics_pubs/25

For more information, please contact repository@pobox.upenn.edu. 


\title{
The measurement of regional cerebral blood flow during the complex cognitive task of meditation: a preliminary SPECT study
}

\begin{abstract}
This study measured changes in regional cerebral blood flow (rCBF) during the complex cognitive task of meditation using single photon emission computed tomography. Eight experienced Tibetan Buddhist meditators were injected at baseline with $7 \mathrm{mCi} \mathrm{HMPAO}$ and scanned 20 min later for $45 \mathrm{~min}$. The subjects then meditated for $1 \mathrm{~h}$ at which time they were injected with $25 \mathrm{mCi} \mathrm{HMPAO}$ and scanned 20 min later for $30 \mathrm{~min}$. Values were obtained for regions of interest in major brain structures and normalized to whole brain activity. The percentage change between meditation and baseline was compared.

Correlations between structures were also determined. Significantly increased rCBF $(P<0.05)$ was observed in the cingulate gyrus, inferior and orbital frontal cortex, dorsolateral prefrontal cortex (DLPFC), and thalamus. The change in rCBF in the left DLPFC correlated negatively $(P<0.05)$ with that in the left superior parietal lobe. Increased frontal rCBF may reflect focused concentration and thalamic increases overall increased cortical activity during meditation. The correlation between the DLPFC and the superior parietal lobe may reflect an altered sense of space experienced during meditation. These results suggest a complex rCBF pattern during the task of meditation.
\end{abstract}

\section{Keywords}

frontal cortex, thalamus, single photon emission computed tomography

\section{Comments}

Postprint version. Published in Psychiatry Research: Neuroimaging, Volume 106, Issue 2, April 2001, pages 113-122.

Publisher URL: http://dx.doi.org/10.1016/S0925-4927(01)00074-9

\section{Author(s)}

Andrew B. Newberg, Abass Alavi, Michael J. Baime, Michael Pourdehnad, Jill Santanna, and Eugene d'Aquili 
Newberg A, Alavi A, Baime M, Pourdehnad M, Santanna J, and d'Aquili E: The measurement of regional cerebral blood flow during the complex cognitive task of meditation: a preliminary SPECT study. Psychiatry Research 4/10/2001;106(2):113-22.

Andrew Newberg ${ }^{\mathrm{a}, *}$, Abass Alavi ${ }^{\mathrm{a}}$, Michael Baime ${ }^{\mathrm{b}}$,

Michael Pourdehnad ${ }^{\mathrm{a}}$, Jill Santanna ${ }^{\mathrm{c}}$, Eugene d'Aquili ${ }^{\mathrm{d}}$

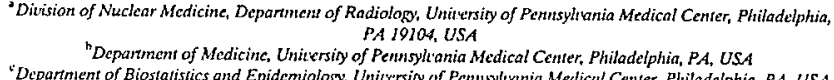

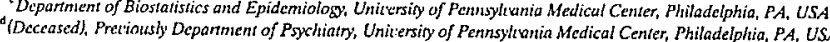

1. Introduction

Meditation, in general, is a complex neurocognitive task that is often associated with alterations in body physiology and psychological measures. Over the past 30 years, a number of studies have explored the physiological correlates of differen types of meditation. It is important to note here that meditation refers to a large variecy of practices that range from purely relaxation-based to fil spiriturmed whe the goal of attaining powermakes the study of sus, This valiation, in liself, ever, we have tried to find similaries an these practices, and feel that cnough prior studies have demonstrated changes associated with these practices that it seems worthwhile to coninue 10 explore them. Several studies have shown that meditation and related practices are associated with changes in the brain's electrical activity as observed on electroencephalography (EEG Anand et al., 1961; Banquet, 1972; Corby et al. 1978; Benson et al., 1990). In particular, increased alpha-wave activity over the frontal regions of the brain has been observed during meditation and the relative strengh of the axpricnce. Other studies have meared different phys. Other changes associated with meditation including changes in autonomic nervous system activity such as those related to heart rate and blood pressure. and changes in cortisol levels (Jeuning et at 1992; Kesterson, 1989; Sudsuang et al., 1991). Despite the avalability of functional imaging (echniques such as positron emission tomography (PET), single photon emission computed tomography (SPECT), and functional magnetic resonance imaging (AMRI), we are aware of only three reports utizing neuroimaging techniques to study subjects practieing medition. In these studies, cerebra function in subject meare changes in tive relaxation techniques (Herzos et al 1990 Lou ct al, 1999; Lazar et al 2000) Because there are many different types of meditation, it is im. portant to evaluate and compare changes associated with different types of meditation to help elucidate the physiological mechanisms underlying the effects of meditation.

In this study, we present the ${ }^{99 m} \mathrm{mc}-\mathrm{HMPAO}$ from eight practivoners of a form of Tiber Buddhisi meditation, performed specifically for spiritual, not-health-related, purposes In this form of meditation, practitioners initially focus heir attention on a visualized image and mainain that focus with increasing intensity. The 'peak' experience of their meditation is described a a sense of absorption into the visualized image associated with clarily of thought and a loss of the ustual sense of space and time. We selected pracitioners of this type of meditation beciuse of heir ability to reproduce the meditative experiSPECT inte being in the laboratory setting. The sures regional cerebral blood flow (CBF), mo correlates closely with cerebral activity. Thus, his technique allowed for a comparison between the rCBF at baseline and during meditation.

We would like to emphasize that SPECT ima ing and the methodology described below wer chosen over other imaging techniques for several important practical reasons. Functional magnetic resonance maging, while having improved resolution over SPECT and the ability of immediat anatomic correlation, would be very difficult to noise from the machine In fact we ause of the use of fMRI with our initint subjoct in order determine feasibility but the subject found extremely difficult to carry out the meditation practice. While PET imaging also provides better resolution than SPECT, our goal was to make the cnvironment as distraction free as possible to maximize the chances of having as strong a meditative experience as possible. In order to achieve this goal, and because of our large research an clinical service, these scans were all performed after hours when fluorodeoxyglucose was no longer available. Thus, while PET and AMRI offer provide the bost option for this inits meditation.

With regards to specific areas of the brain that might be involved during meditation wo 

focus of this study. (1) Several investigators, cluding our group, have postulated increased ac tivity in the frontal lobes, and in particular the prefrontal cortex, during meditation. This notion is based, in part, on the above-mentioned EEG which have found increased frontal activity during attention-focusing tasks (Mizuki 1983; Fith at, 1991; Pardo et al. 1991). (2) Meditation also associated with alterations in the subjective experience of space and time. We have postulated that there should be decreased activity in the superior parietal lobe since studies have show this area to be involved with visual-spatial and temporal processing as well as body orientatio (Lynch, 1980; Joseph, 1996). Furthermore, studie activity in the fro have de creased activity in the association areas. Thus, there should be a correlation between relaive increases in the frontal lobes and relative decreases in the superior parietal lobes (Frith et a 1991). (3) Meditation subjects often describe decreased sensory awareness and decreased moto activity, and we therefore predicted a decrease the activity in the sensorimotor area. (4) These may be changes in the midbrain related to autonomic changes associated with meditation We bellum, the superior frontal cortex and the cecipital lobes since no studies hat implicated these areas as involved in meditation.

We also considered the possibility that there may be baseline differences in rCBF berween subjects who practice meditation and those without such experience. In order to test this hypothesis, baseline rCBF in the meditation subjects was compared to that in a group of control subjecs who were recruited for other, unrelated studics.

\section{Methods}

2.1. Subjects and imaging acquisition

Eight subjects with no history or clinical evi- dence of medical, neuropsychological, or drug abuse that would potentially alter CBF, were recruited to participate in this study. Four were from 38 to 52 years with a wean age of 45 years Each subject described himself or herself as practicing Tibetan Buddhist meditator with morc than 15 years of experience, usually including month retreat. They have meditaced mately $1 \mathrm{~h}$ per day, and at least five days a week. On the day of the study, after obtaining informed consent (approved by the Human lnstitutiona Review Board with the study protocol), a room was set up in the hospital to function as a medita tion room. Subjects were allowed to use incenso throughout the baseline and meditation scans. Approximately $20 \mathrm{~min}$ prior to the baseline scan an intravenous canula (IV) was placed in on from the iv that resolved prior to iniscomfor remainder of the study. Subjects were introcted to rest in the room with their eyes closed and ear noccluded for 5-10 min at which time they were injected through the IV with $7 \mathrm{mCi}$ of ${ }^{99 \mathrm{~m}} \mathrm{Tc}$. HMPAO (Amersham Intemational, Arlington Heights, IL, prepared as specificd by the manufacturer). Thiry minutes following the injection, the subject was scanned for $45 \mathrm{~min}$ in Picker-Pris (Picker lnc., Cleveland, $\mathrm{OH}$ ) triple-headed rotating gamma camera using mates were obtained as threc decrec angle intervals on a $128 \times 128$ matrix (pixel size $3.56 \times 3.56$ $\mathrm{mm}$ ) over $360^{\circ}$ by rotating each head $120^{\circ}$. SPECT images were reconstructed in the transaxal, coronal, and sagittal planes using filtered backprojection, followed by a Weiner post filter and 1st order Chang attenuation correction. The reconstructed slice thickness was $4 \mathrm{~mm}$ with spatial resolution of $8-10 \mathrm{~mm}$.

Nine control subjects, recruited as a group of healthy controls for other activation studies, had undergone a baseline SPECT imaging scan simiof the control subjects ave. The baseline scans baseline scans of the meditators to assess baseline changes in the meditation subjects.
Following this 'baseline' scan, the subject returned to the room for meditation. They were allowed to sit comfortably on pillows to maintain their usual posture during the meditation. They were also allowed to utilize several meditation books initially, although they had their eyes closed (their ears were also unoccluded) during approximately the final 30 min of the meditation, including during the time of the second injection of and the door of the room was lo a mininum meditation. The subect matited for app the mately 1 h at which time the subject provided 'signal', observable to the investigators, that was incorporated as part of the meditation proctice (because of the use of this signal that marked when the subjects were about to begin the most intense part of the meditation, we felt that concurrent measurement using electroencephalography to determine if subjects were aslecp was not hecessary). Several minutes after this signal, the subject was injected with $25 \mathrm{mCi}$ of ${ }^{99 \mathrm{~m}} \mathrm{Tc}$ tion while he/she continued to meditate for subject) mately another $10-15 \mathrm{~min}$ maintaining the same intensity of meditation. The meditation session was ended, and $30 \mathrm{~min}$ after this injection the subject was then scanned ('meditation' scan) for 30 min using the same imaging parameters as for the baseline study.

2.2. Image analysis and statistics

Several different statistical approaches were used in order to answer the questions raised by used in order
our hypotheses.

2.2.1. Region of interest analysis

The images of the baseline and meditation scans were reconstructed and resliced, using an oblique reformatting program, according to the anterior-posterior commissurc line so that the hial tho sets were al comparable anatomical sites for the analysis. A previously validated template (ROI) subcortical structures was placed over the base-
Ine scan (Resnicn et al., 1993). For the purposes of this study, we examined the $\mathrm{r} C \mathrm{CBF}$ as measured in only a selected number of ROIs, which was hypothesis driven. The ROIs examined were the -frontantal, superior frontal, dorsolater protrontal, orbitofrontal, dorsal medial cortex,

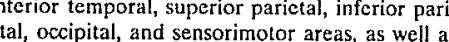
the caudate, thalami, midbrain, cerebellum, an cingulate gyrus. Each ROI (which is small and therefore represents a 'punch biopsy' of any given der to achieve the best fit according to the ar The ROls were then copied directly onto the meditation scan. This was possible because the The resliced into the same planes as described above. The count values for the meditation scans were obtained by determining the number of counts in each ROI on the meditation scan and subtracting the number of counts in the same ROI on the bascline scan which were decay corrected to the midpoint of the two scans. both the baseline and malized to the whole brain activity. This provor an $\mathrm{rCBF}$ ratio for each ROI compared to the whole brain. A percentage change was calculatco using the equation:

$\%$ Change $=\frac{(\text { Meditation }- \text { Baseline })}{1 / 2 \times(\text { Meditation }+ \text { Baseline })}$

$\times 100$

A laterality index (LI) was also calculated to determine the relative activity of homologous refollowing equation:

$\mathrm{LI}=\frac{(\text { Right }- \text { Left })}{1 / 2 \times(\text { Right }+ \text { Left })} \times 100$

A mixed model analysis was used to comparc bascline and meditation $\mathrm{rCBF}$ using data from both the left and right brain hemispheres. The mixed model was necessary to adjust for the correlation between millple observations collected

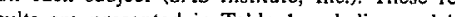




\begin{tabular}{|c|c|c|c|c|c|}
\hline Part of the brain & P.value & $\begin{array}{l}\text { Basclinc } \\
\text { trean }\end{array}$ & $\begin{array}{l}\text { Mcditation } \\
\text { mean }\end{array}$ & $\begin{array}{l}\text { Percent } \\
\text { change }\end{array}$ & $\begin{array}{l}\text { Standard } \\
\text { deviation }\end{array}$ \\
\hline Anterior cingulate & 0.0074 & 1.25 & 1.34 & 7.2 & 0.08 \\
\hline $\begin{array}{l}\text { Cingulate body } \\
\text { DLPFC }\end{array}$ & 0.0001 & 0.91 & 1.14 & 25.3 & 0.13 \\
\hline $\begin{array}{l}\text { DLPFC } \\
\text { Inffrior frontal }\end{array}$ & $\begin{array}{l}0.06025 \\
0.0025\end{array}$ & $\begin{array}{l}1.31 \\
125\end{array}$ & $\begin{array}{l}1.45 \\
1.36\end{array}$ & $\begin{array}{r}10.7 \\
8.8\end{array}$ & 0.08 \\
\hline & 0.0166 & 1.20 & $\begin{array}{l}1.36 \\
1.29\end{array}$ & 8.8 & 0.09 \\
\hline Ortitial frontal cortex & 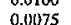 & $\begin{array}{ll}0.169 \\
0.07\end{array}$ & 1.129 & $\begin{array}{l}11.2 \\
258\end{array}$ & 0.14 \\
\hline Posterior cingulate & 0.0114 & 1.19 & 1.29 & 84 & 0.09 \\
\hline Sensorimotor & 0.0017 & 1.19 & 1.26 & 5.9 & 0.06 \\
\hline Thalamus & 0.0114 & 1.40 & 1.60 & 14.3 & 0.21 \\
\hline Dorsomedial cortex & 0.0154 & 1.26 & 1.31 & 4.0 & 0.06 \\
\hline Superior parictal & 0.1715 & 1.18 & 1.12 & -5.0 & 0.11 \\
\hline Caudate & 0.5743 & 1.29 & 1.32 & 2.3 & 0.13 \\
\hline crebellum & 0.2534 & 1.23 & 1.25 & 1.6 & 0.04 \\
\hline ivperior frontal & $\begin{array}{l}0.2486 \\
0.7484\end{array}$ & 1.29 & 1.34 & $\begin{array}{r}3.9 \\
-0.9\end{array}$ & 0.13 \\
\hline
\end{tabular}

the results section. An analysis of the laterality indices for ecch homologous pair of ROIs in the ing a two-tailed Studeni's $t$-test.

2.2.2. Statistical parametric mapping (SPM) The image volumes of iransverse slices were headers for the images. For each image, a file was created that contained dat on image size num. ber of slices, pixel depth, maximal pixel value, and voxel size. All slices of a brain image were sam. pled and averaged to arrive at a mean pixel intensity for that image. The intensity threshold was set at $60 \%$ of the whole brain value. The images were spatially normalized in SPM to a standardized stereotactic space based on the atlas ization and Tournoux (1988). The normalsmoothin 10 a total of $12 \mathrm{~mm}$. The significa threshold for increased activity was set at $P<$ 0.01 , and that for decreased activity was set $P<0.001$ ( $(Z>3.20)$ comparing the expected and observed number of pixels above the threshold (Friston ef al., 1995). The location and peaks of significant increases and decreases were obtained. The cerebral structures were identified by their Talairach co-ordinates.
2.2.3. Correlations between brain structures Pearson correlations were generated to assess the association between changes in $\mathrm{rCBF}$ values in different regions. Significance tests for the posterior superior parictal lobe, dorsolateral premotor cortex since these wer the ares would most likely interact with each other durin the task of meditation. Because of the small sample size, all results were confirmed using Spearman correlations. The results of both methods were similar, so only Pearson correlations will be presented.

2.2.4. Baseline changes in meditators compared to controls

Using a two-tailed Student's -test, the $\mathrm{rCBF}$ values at baseline for the meditators were compred to those of a group of healthy control underwent a similar basel SPECT studies, who

\section{Results} this study are shown in Table 1 (see also Fig. 1). correlations were limited to the structures of the

The results of the mixed model analysis from
Relative $\mathrm{CBF}$ increases were observed in the infepreffontal cortices, the sensorim, dorsomedial cortices, the midbrain, the cingulat gyri, and the thalami. The other regions showed no significant changes in activity. The laterality

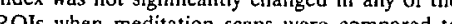
the baseline.

Thes 2 and 3 from the SPM analysis are shown in Thereases were only found in the etal lobe, the right lateral in the superior pariinferior temporal lobes. While these findings corroborate some of the ROI results, other areas observed to be increased on the ROI analysis were not observed to be significantly different on the SPM analysis. This may be due to the overmall chune nathe tion state. Furthermore the small number of subjects lead to a false-negative result with SPM analysis. We did not observe a significant change in the inferior temporal lobes in the ROI analysis, but this may be due to the relatively large area that was used for this particular region.

There were several significant correlations between the change in activity in certain structures. The change in activity in the left dorsolattively with the change in activity in the left posimus $(r=0.71, P=0.049)$. The change in activity in the right DLPFC correlated positively with the change in activity in the right thalamus $(r=0.71$ $P=0.05$ ). The change in activity in the left DLPFC correlated negatively with the change in activity in the left superior parietal lobe $(r=0.76$, $P=0.03$ ).

There were no significant differences observed between the baseline scans of the meditators and control subjects. The laterality index was calculated for several regions including the frontal crly nos the and control subjects was observed in the thalami. In the thalami, the meditation group bat a base line laterality index of 9.97 , which was significantly different compared to the baseline lateral-
Table 2

Location and peaks of significant $(P<0.01)$ increase in

\begin{tabular}{lcccl}
\hline Structure & \multicolumn{3}{l}{ Co-ordinates } \\
\cline { 2 - 5 } & $x$ & $y$ & $z$ & $z$ score \\
\hline R thalamus & 4 & -8 & 6 & 3.64 \\
R thalamus & 10 & -24 & 2 & 3.39 \\
\hline
\end{tabular}

ity score of the control group $(3.78, P=0.03)$. No other significant differences were observed in ther the laterality index or $\mathrm{rCBF}$ values belwe the meditation and control group. Interestingly, the laterality index in the meditation group moved toward the value of the control group on the meditation scans. However, this change in laterality index was not statistically significant.

\section{Discussion}

Regarding our initial hypotheses, the first was that we expected lo observe an increased level or prefrontal areas. Several studies have exam the the effects of the complex neurocognitive task of meditation on brain activity. Most of these studies involved electroencephalographic (EEG) measurements during meditation in comparison to baseline (Corby et al., 1978; Banquet, 1972). Proficient practitioners usually have been shown 10 have increased alpha and theta amplitudes, parline (Hivai, 1974). These ches, compred to baseciated with increased autonomic activation. One

Table 3

peaks of significant $(P<0.001)$ decreasc in Whod flow during meditation

\begin{tabular}{|c|c|c|c|c|}
\hline \multirow[t]{2}{*}{ Structure } & \multicolumn{4}{|c|}{ Courdinutes } \\
\hline & $x$ & $y^{\prime}$ & $z$ & $z$ scure \\
\hline $\begin{array}{l}\text { R superior parictal } \\
\text { L superior parictal } \\
\text { R f laterat temporal }\end{array}$ & $\begin{array}{r}18 \\
-16 \\
62\end{array}$ & $\begin{array}{l}-68 \\
-58 \\
-30\end{array}$ & $\begin{array}{l}56 \\
50\end{array}$ & $\begin{array}{l}3.59 \\
3.50 \\
3.39\end{array}$ \\
\hline $\begin{array}{l}R \text { lateral temporal } \\
\text { L inferior temporal }\end{array}$ & $\begin{array}{l}-46 \\
-46\end{array}$ & -72 & -2 & $\begin{array}{l}3.39 \\
3.29\end{array}$ \\
\hline
\end{tabular}




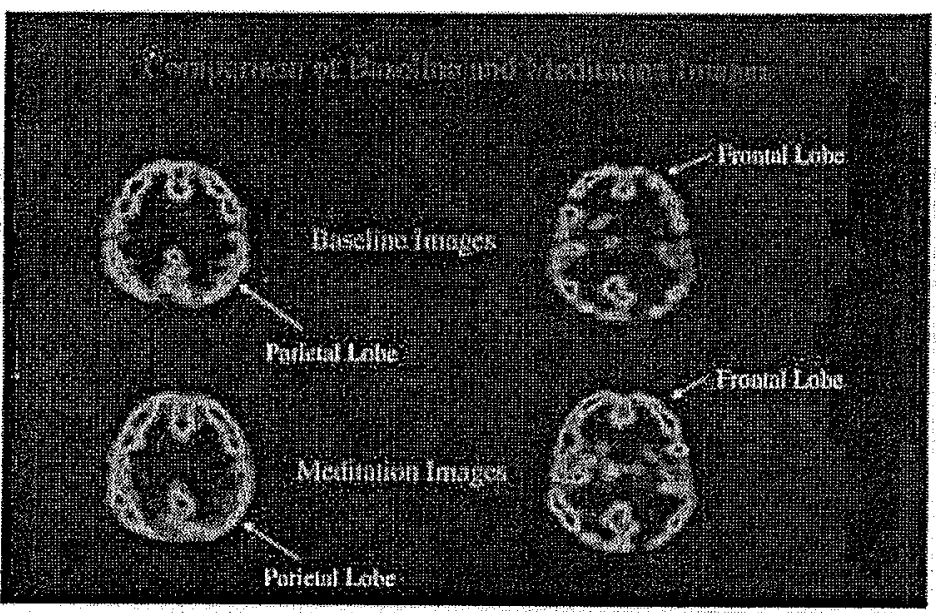

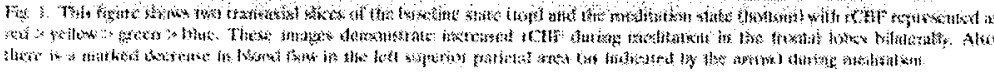

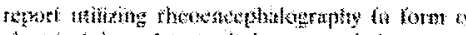

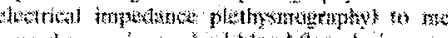

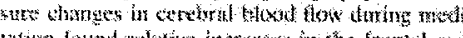

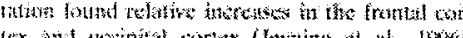

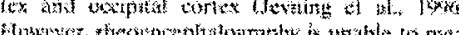

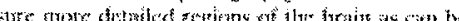

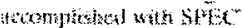

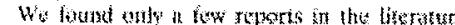

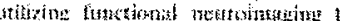

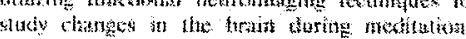

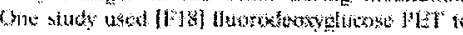

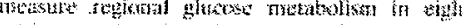

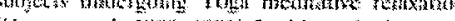

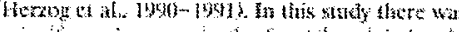

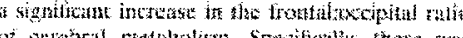

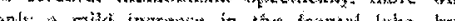

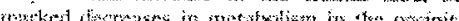

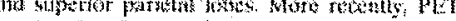

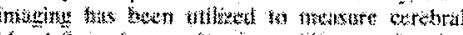
Yod

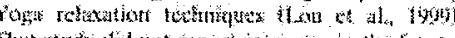

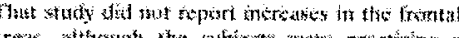

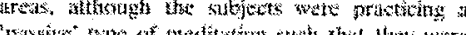

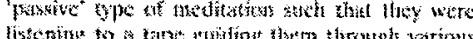
twedien

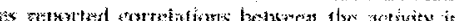

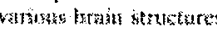

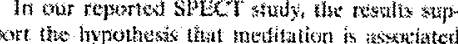

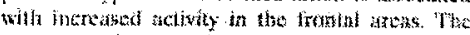

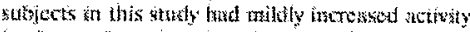

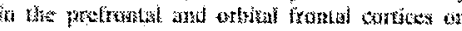

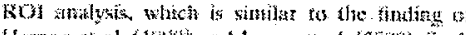

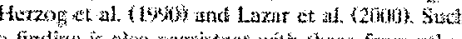

studies which have shown increased activity in the ing tasks (Frith et al., 1991; Pardo et al., 1991). The increased activity observed during meditation in our study and others is most likely related to the active process of meditation in which subjects willfully concentrate upon their meditation. The study by Lou et al. (19) did not demonstrate disting. Hower, one of the inportant tened to a tape that guided them through meditation. Thus, the participants were much more passive than the subjects in our study. Stud ies which have shown increased activity. in the frontal lobes during concentration tasks would suggest that the more a person actively focuses attention, the more likely there is to be an increase in the frontal lobe activity. Thus, the in creased frontal activity in the SPECT study presented here is consistent with the active are tion-focusing component of this type of activ meditation.

Our second hypothesis was that there would be a relative decrease in activity of the supcrior paretal areas associn af whe sense of an (d'Aquili and Newbers 1993). While we did no find a significant decrease in the superior parient lobes on ROI analysis, there was an overall tren in this direction and we did find decreased activity on the SPM analysis. More importantly, the increased activity in the left prefrontal cortex correlated significantly with the decreased activity in the left superior parietal lobe. Several studies have shown that there are alterations in activity in the superior parietal lobe, particularly in association with increased activity in the prefrontal cortex, in subjects performing visual-spatial task (Cohen et al., 1996; D'Esposito et al., 1998). Thus, these studies not only suggest that the superio parietal lobe is associaled with spatial processing, during such processing The corrotion betwe the change in activity of the prefront cortex and the superior paris lobe profron SPECT and sugesis that such an interaction may also occur during meditation. However, more detailed stud- ies will be necessary to corroborate and expand such findings.

Our third hypothesis was that there would be a relative decrease in activity of the sensorimotor areas since meditation has the specific goal of reducing external distraction including sensory stimuli and body movement. Our findings demonstrated an increased level of activity in these areas, which appears to contradict this hypothesis. Is possible hat whe extrancous sensory and significant degree of mor activity maintain the subject's posture and thcro may at least be some form of visual input from the internal imapes generated during this type of meditation. This, of course, is speculation, and future studies are necessary to explore the relationship of the sensorimotor cortex to meditative practices.

Meditation has frequently been associated with alterations in autonomic nervous system activity. Studies of meditating subjects have often rcported decreases in blood pressure, heart rate, and changes in galvanic skin responses (Jevning et al., 1922, Sudsuang et al., 1991). We and others pave prophed and the meditation process (d'Aquili and Newing 1993; Peng et al, 1999). The increase Newberg, the midbrain observed in this study may be asso. cialed with alterations in autonomic activity during this type of meditation. However, such conclusions regarding the basis of increased midbrain activity require further studies for clarification, especially since we did not specifically measure autonomic function

We had also hypothesized that we would not see significant changes in the cerebellum, superor frontal, or occipital areas since these do not contribute functions that might be expected to be related to the practice of meditation. However, hat interesting finding that was nol expected was that there was significantly increased activity in major cortical and corticat-subcorical relay. The lamic activity might be important for the overall complex proceses wo believe to bo associnte 
with meditation, which includes both cognitive and affective responses.

aican group had a sig. baseline compared to controls supports the at tion that meditating subjects may have changes in their brain at rest. This is an interesting finding that needs to be explored by examining a larger sample of subjects. We only examined eight laterality scores and for this reason did not perform Bonferroni correction; however, only the thalamic laterality was found to be significantly differen. Moreover, if baseline diferences between the two groups are substantiated in future studies, the cunction is related to many years of meditation practice, or if these subjects were born with such a distinction which might have predisposed them to adopt meditation during their lives. Answers to such questions remain purely speculative at this time.

We present this preliminary study to illustrate several points regarding the measurement of rCBF during meditation. We have shown a simple method by Which HMPAO SPECT can be used to detect changes in rCBF during Tibetan Buddhis to other forms of mpatation to explore whether different types of meditation are associaced with different neurophysiological correlates.

Patential confounding problems with this study include the fact that the subjective sense durin the meditation is difficult to measure. We had subjects fill out questionnaires after the study, bu found that the subjective responses were impossico to que However, all subjects felt that they had had an measures, while potentially providing additiona interesting information, would also not have been able to confirm the specific subjective state, such as the depth of the meditation, of each subject during the study. We also did not feel that EEG was necessary to exclude the possibility that the subject had fallen asleep because required hand signals demonstrated that subjects were awake. However, now that we have shown evidence for changes occurring during meditation, future studies will need to explore how cerebral activity as measured by EEG patterns and neuroimaging

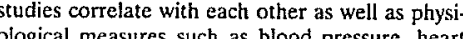
rate, and respiratory rate. This study also hear sured $\mathrm{rCBF}$ at a single point during also meawhich is obviously a lengthy process that requires time for various cognitive and affective responses to occur. Thus, the images are taken only during the assumed peak of meditation and may, in fact, reflect activity during some other component of the meditation. The study has a limited number of meditation subjects since it is most difficult to find highly experienced meditators. While this subjects is the statistical analysis, the number of of other types of meditation and was enoudies reveal statistically meaningful results. Finally, while FMRI and PET have taken the lead in brain activation studies and both methads provide technical advantages over SPECT, meditation presents the particular problem of requiring a quiet, distraction-free environment. To provide this, MRR would be too noisy and fuorodeoxyglucose for PET studies is often not available during the limes that these istudies are best performed. Howamenable to the sudy of mediation more fruitful in helping to better define the underlying physiological basis of such practices.

\section{Conclusion}

The results from this initial study have begun to elucidate the neurophysiological correlates of complex cognitive functions such as meditation. The findings also support our hypotheses that the fron is associated with increased activity in lated with decreased activity in the posterior pare clal lobes. These two findings, respectively, may be attributable to the increased attention of subjects and the experience of alterations of the ense of space. That there were also changes in ctivity in the thalami, sensorimotor cortex, and midbrain suggests that there is an intricate level of central nervous system interactions during this type of meditative practice. Future imaging re search should explore the cerebral correlates of meditation in a larger number of subjects as well as incorporate other physiological and neurophyslological measures. Such studies will be essential to elucidate the basic mechanisms that underlie cojective and clinical observar

\section{References}

Anand, B.K., Clina, G.S., Singh, B., 1961. Some aspects of clectrochecphalognaphic sludies on yogis. Electroen-

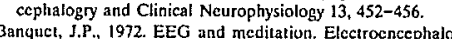
gry and Clinical Neurophysiology 33, 45. Benson, H., Malhoura, M.S., Goldman, R.F., Jacohs, G.D. Hopkins, P.J., 1990. Three case reports of the metatolic Buddhist meditation lechuiques. Bchavioral Medicine 16. 90-95.
Cohen, M.S., Kosslyn, S.M., Brciter, H.C., DiGirulamo, G.J., Cohen, M.S., Kosslyn, S.M., Brciter, H.C., DiGirolamo, G.J.,
Thompson, W.L. Anderson. A.K., Buokheimer, S.Y.

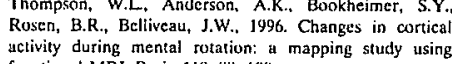

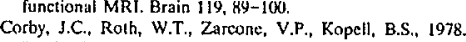
Psychophysialagical correlates of the practioc of Tantric
Yoga meditation. Archives of General Psychiatry 35,
$571-577$ JAyuili, E.G. Newberg, A.B., 1993. Religious and mystical Esposito, M., Aguirre, Q.K., Zarahn, E., Ballurd, D., Shin R.K., Lease, J., 1998, Functional MRI studies of spatial and 1-13.

Friston, K.J., Holmes, A.P. Whrstey, KJ., Polinc, J.P., Frith,
C.D., Frackowiak, R.S.J., 1995. Statistical paramerric maps C.D., Frackowiak, R.S.J., 1995. Statisitical paramertic maps
in functional imaging: a gencral lincar approacl. Humarn

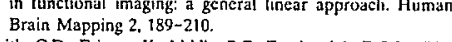
Willed action and the preftrontal corcex in, man. A study Royal Socicy of London 244.

Hernog, H., Lelc, V.R., Kuwert, T., Langen, K.J., Kups, E.R.,
Feinendegen. LE.,

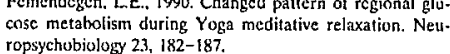

Hirai, T., 1974. Psychophysiology of Zen. Igaku Shuin. Tukyo. Evning, R., Anund, R., Biedebach, M.. Fernando. G., 1996.

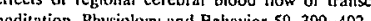

aloy of mediation megrated response. Neuroscicnec and Biobehavioral Re-

Joseph, R., 1996. Neurapsychology, Neuropsychiatry, and Be-

and a panca during medtititation. Americatan Journal of Physiollogy R256, $632-638$.

Lazar, S.W., Bush, G., Gollub, R.L., Fricchionc, G.L., Khals G.i, Benson, $H_{1,}$ 2000. Functional brain mapping of the
relaxation response and meditation. Neurorcport 11 , 1581-ics.

Lou. H.C., Kjacr, T.W., Friberg, L., Wildschiodtz, G., Holm, Nowak, M., 1999. A "O-H $\mathrm{H}_{2} \mathrm{O}$ PET study of meditatio and the resting state of
Brain Mapping 7, 98-105.

Lynch, J.C., 1980. The functional organization of posterior parictal 2 a.
$485-499$.

Mizuki. $Y$., 1983. The relationship between the apperancec of Electrovencephalography and Clinical Neurophysiologeg Japan EEG/EMG Socicry Proccedings $56,56$.

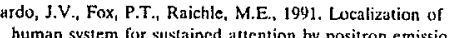
tomography. Nature 349, 61-64.

eng, C.K., Mictus, J.E., Liu, Y., Khalsa, G., Douglas, P. Benson, H.. Goldberger, A.L, 1999. Exaggerated heart rate oscillations during two meditation techniques, Internatio-
nal Jounnal of Cardiology $70,101-107$.

parison of anatomically defined vis. phe R.E., 1993. Conregionat localization: vffects on PET-FDG quantitiation SAS Insitite, IEC, SAS/STAT S

hancements Through Relense 6.12 Cary. NC. SAS InstituInc., p. 1167.

Sudsuang. R., Chentanez, V., Veliuvan, K., 1991. Effect of Buddhist meditation on serum cortisul and total prottin

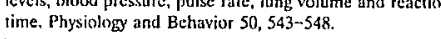

of the Human Brain. Thieme. Stutgart 